\title{
(2) OPEN ACCESS \\ Animal researchers shoulder a psychological burden that animal ethics committees ought to address
}

\author{
Mike King (ㄷ), ${ }^{1}$ Hazem Zohny (i] ${ }^{2}$
}

1 Bioethics Centre, University of Otago, Dunedin, New Zealand ${ }^{2}$ Oxford Uehiro Centre for Practical Ethics, University of Oxford, Oxford, UK

\section{Correspondence to}

Dr Hazem Zohny, Oxford Uehiro Centre for Practical Ethics, University of Oxford, Oxford, UK; hazem.zohny@philosophy.ox. ac.uk

Received 24 September 2020 Revised 3 December 2020 Accepted 2 March 2021

\section{Check for updates}

(c) Author(s) (or their employer(s)) 2021. Re-use permitted under CC BY-NC. No commercial re-use. See rights and permissions. Published by BMJ.

To cite: King M, Zohny $\mathrm{H}$. $J$ Med Ethics Epub ahead of print: [please include Day Month Year]. doi:10.1136/ medethics-2020-106945

\section{ABSTRACT}

Animal ethics committees (AECs) typically focus on the welfare of animals used in experiments, neglecting the potential welfare impact of that animal use on the animal laboratory personnel. Some of this work, particularly the killing of animals, can impose significant psychological burdens that can diminish the well-being of laboratory animal personnel, as well as their capacity to care for animals. We propose that AECs, which regulate animal research in part on the basis of reducing harm, can and ought to require that these harms to researchers are reduced as well. The paper starts by presenting evidence of these burdens and their harm, giving some examples showing how they may be mitigated. We then argue that AECs are well placed to account for these harms to personnel and ought to use their power to reduce their occurrence. We conclude by responding to four potential objections: (1) that this problem should be addressed through health and safety administration, not research ethics administration; (2) that the proposal is unjustifiably paternalistic; (3) that these harms to laboratory animal personnel ought to occur, given their treatment of animals; and (4) that mitigating them may lead to worse treatment of research animals.

\section{INTRODUCTION}

In March 2020, when policy responses to the COVID-19 pandemic forced research laboratories across the world to shut down suddenly, a consequence of this was that rats, mice and other animals had to be killed in order to manage research activities under lockdown. Although regrettable with respect to both the loss of valuable animal life, and the setback to research, it would have been impossible in most cases to ensure ongoing animal welfare while still observing restrictions of movement in response to the pandemic. There are many ways laboratory animals can be killed, but a common method for rats or mice is to subject them to carbon dioxide inhalation, and then, to ensure death, each animal may be cervically dislocated at the neck.

Killing animals in or at the conclusion of research, and in management of colonies of animals bred for research, is common, but the suddenness of the closure meant that this workload was greater, with reports of individual researchers having to personally kill hundreds of mice and rats in 1 day. ${ }^{1}$ They describe this work as taking a psychological toll on them: emotionally and physically overwhelming, and 'morally exhausting'. 1 There are many such reports, ${ }^{2-4}$ although some laboratories have found alternatives to killing. ${ }^{5}$

This response to the pandemic highlights an issue relevant for the committees that provide ethical regulation of research involving animals - the burden of animal research on the researchers, as well as the animals. Some of the work of animal laboratory personnel can involve inducing disease or damage in healthy animals they care for, depriving animals of usual care, and often-as in the case of the pandemic - killing them for reasons unrelated to relieving their pain or distress. If aspects of research such as these can set back the well-being of animal laboratory personnel by negatively affecting them psychologically, this seems, prima facie, to be harmful, and relevant for the purposes of ethical review.

In the argument of this paper, we make the plausible assumption that the killing of animals in research is likely to persist for some time, and that, even with significant legal reform, it may still be legally and ethically justifiable when it is necessary to pursue potential benefits of sufficient magnitude, or when necessitated by emergencies, such as the COVID-19 pandemic, as explained earlier. In this paper, we refer to the act of intentionally ending life as killing, drawing on its standard meaning, which is to cause death, especially intentionally. In doing so, our aim was to be descriptively accurate, not ethically evaluative or sensational. Sometimes, animals are killed in order to prevent or end pain or suffering (euthanasia). Animals are also killed in research for reasons unrelated to their welfare-enabling postmortem observations, or because there is no research need for them. Our argument applies to all of these instances, hence our use of 'killing' as a term that refers to any of them.

We think the pandemic highlights the need for reform on how killing, inducing disease or injury, and observing morbidity in research animals, is regulated and conducted. We argue that this reform can unfold by having the committees that provide ethical oversight of animal research include assessing and minimising the potential harm to animal laboratory personnel from research on animals. We use 'animal laboratory personnel' as an umbrella term for laboratory managers, researchers, veterinary technicians or technologists, or any personnel who interact with animals in research settings. In what follows, we first describe the nature of this harm and substantiate its regular occurrence. We then move on to discuss some of the ways animal ethics committees (AECs) can account for these harms. Finally, we respond to potential objections, none of which we believe are fatal for our argument.

\section{WELFARE IMPACT OF HARMING ANIMALS IN RESEARCH}

Many laboratory animal personnel are directly or indirectly involved in caring for laboratory animals, often forming attachments to them. ${ }^{6}$ These same personnel often have to perform or view procedures 
that harm these animals, and almost all these animals are then killed at the end of a study for tissue analysis, or because they cannot be used in other studies, or because they are not rehomed outside the laboratory.

This is what is sometimes called the 'caring-killing paradox' in research ${ }^{7}$ and links to compassion fatigue, ${ }^{8}$ or perpetrationinduced traumatic stress ${ }^{9}$ and more specifically, 'euthanasia stress ${ }^{10}$ or moral stress. ${ }^{11}$ These refer to an array of harms to animal laboratory personnel associated with physical and emotional distress that can also impact the quality of care and welfare attention given to animals. ${ }^{12}$ There is some disagreement about the nature of compassion fatigue, and some have argued it is a misnomer, that in fact it is empathy, not compassion, that can lead to the burn-out and other associated harms that are observed..$^{13}$ For our purposes, we are concerned about the overall negative welfare impact on laboratory animal personnel arising from harming animals used in research, and the factors that influence their occurrence and extent. Our focus is specifically on instances where that negative welfare impact is significant: intense, extended in duration or repetitive, and with the potential to disrupt their capacity to optimally fulfil their roles. We will hereafter refer to that significant level of harm collectively as animal user burden (AUB).

The procedures involving research animals differ from species to species, and here we focus mostly on rodent laboratory animals, especially mice and rats. These make up the bulk of laboratory animals ${ }^{\mathrm{i}}$ and are more likely for personnel to form attachments to, compared with, for example, fish. Experimental procedures can involve inducing disease or injury in animals, performing non-therapeutic surgery, restraining animals or depriving them of normal care, and tissue sampling. For instance, in the UK in 2019, animal laboratory personnel conducted over 70000 severe experimental procedures on rodents, which entail major departures from animals' usual health or well-being, including long-term disease and persistent significant deficits in behaviour/ activities. $^{14}$

Killing can involve administering lethal injections, decapitation or inhalation of $\mathrm{CO}_{2}$ gas, among numerous other options. ${ }^{15}$ Some protocols require personnel to perform cervical dislocation on mice who have already been rendered unconscious or dead by $\mathrm{CO}_{2} \cdot{ }^{16}$ This procedure involves securing the base of a rodent's skull with hands or a rod, then quickly pulling the base of the tail or the hind limbs, separating the cervical vertebrae from the skull. ${ }^{15}$

How psychologically taxing these procedures are on personnel varies: higher degrees of pain or stress experienced by animals corresponds with higher AUB among laboratory animal personnel. ${ }^{17}$ Moreover, while the evidence for the impact of euthanasia frequency on AUB is mixed, ${ }^{\text {ii }}$ lack of control over the performance of euthanasia (eg, when, by whom and how) appears to be a significant contributor to its occurrence and extent. ${ }^{17}$ In the case of COVID-19 lockdowns and the culling of colonies, there was little control. Crucially, personnel who are required to use physical methods, such as cervical dislocation, reported higher AUB. ${ }^{17}$

Indirect evidence also comes from Hayes and colleagues, ${ }^{18}$ who found that high emotional exhaustion, depersonalisation

${ }^{\mathrm{i}}$ Of the 1.73 million experimental procedures carried out in the UK in 2019 on living animals, over $61 \%$ were on mice. ${ }^{14}$

${ }^{i i}$ Though many of the studies that find no effect do not take into account the high degree of personnel turnover in animal care that typically occurs within the first year when they are first exposed to animal killing. and low sense of personal accomplishment were common among veterinary technicians working in clinical veterinary practice. Other survey responses indicate that veterinary technicians suffer cognitive dissonance associated with laboratory animal medicine,${ }^{19}$ which is associated with negative emotional states. Similar findings also support a strong link between personnel involved in animal laboratory killing and higher levels of work stress and lower job satisfaction. ${ }^{80}$ In particular, AUB is associated with high rates of employee absenteeism and high personnel turnover, and can affect the quality of animal care and increase mistakes and safety breaches. ${ }^{10}$

\section{MITIGATING AUB}

There is a need for more research on ways of mitigating AUB, but a number of steps may be undertaken while empirical investigations for the best methods continue. Suggestions have included

- Ensuring training in stress management techniques and the ability to recognise symptoms of AUB. ${ }^{10}$

- Promoting open dialogue about AUB and its impact on personnel's health, including mental health, and behaviour. $^{1012}$

- Ensuring availability of counselling to personnel and ensuring counsellors are knowledgeable about AUB and its impacts. ${ }^{10}$

- Dividing emotional labour in ways that may help dilute individual emotional burdens. ${ }^{11} 12$ This may also afford personnel more control, which as noted appears central to mitigating AUB. ${ }^{17}$

Elaborating on this final point, as noted, we found that the procedures for making euthanasia decisions can affect AUB among animal laboratory personnel, and having very clear criteria for determining when an animal should be killed can help mitigate AUB by bringing greater clarity and predictability. Borrowing techniques from other caring professions may also be considered. For instance, job rotation has been recommended for emergency room nurses as a way to specifically mitigate compassion fatigue, ${ }^{21} 22$ which has also been recommended for staff involved in or affected by euthanasia in animal shelters, along with breaks during the day and time off to relieve stress. ${ }^{23} 24$ There is also a burgeoning self-help literature on combating compassion fatigue in different caring professions, though it is unclear how effective some of these recommendations are (eg, see $S_{\text {mith }}{ }^{25}$ ).

Other possible measures may include recommending refinements to methods of killing to reduce AUB impact, such as avoiding 'physical' techniques (eg, cervical dislocation, blunt force trauma and captive bolt) and provision of environmental enrichment for animals, which, aside from their benefit for animals, have a positive impact on the welfare of animal laboratory personnel. ${ }^{17}$ It is beyond the scope of this paper to assess these, and it would be desirable to have more research to enable that assessment, as well as to develop others.

\section{ROLE FOR AECS}

Any harm or benefit caused by research is, prima facie, ethically relevant, to the extent that ethical theories generally concern themselves to some degree with protecting and promoting wellbeing. Given this, AECs, which regulate animal research in part on the basis of reducing harm, can and ought to reduce the extent of AUB.

We use the term AECs to refer to any oversight body that regulates animal-based research by reviewing individual projects 
on the basis of ethical criteria. These are called Animal Ethics Committee in New Zealand, Animal Welfare and Ethical Review Body in the UK, Institutional Animal Care and Use Committee in the USA. ${ }^{26-28}$ Their rationale is ethical protection of the animals used in research; much of the focus of ethical review is to reduce the harm done to animals in research, and to ensure any harm that remains is justified. The three Rs are a mainstay of animal ethics review and therefore ethical animal research design. These consist of reducing the number of animals used in research to a methodologically satisfactory minimum, refining experimental techniques to improve animal welfare and replacing animals with the capacity for welfare (usually equated with sentience) with alternatives that lack it when these satisfy experimental purposes. With welfare impact reduced in this way, the expected harm of the research to animals is weighed against its potential benefits, with the meeting or exceeding a threshold of potential benefit being necessary for the experiment to be permissible. ${ }^{26-28}$

AECs are therefore in the business of assessing the welfare impacts of animal research. This is not limited only to the welfare of animals but can also include the welfare of humansoften as potential beneficiaries of the results of the research. Yet, despite this, the ethical analysis does not include the well-being of animal laboratory personnel, let alone AUB, as an explicit focus. ${ }^{\text {iii }}$ We will not speculate on why this is so; the ethical question we consider is whether AECs ought to include consideration of AUB since this is a potential ethical cost of research.

Imagine an AEC receives an application that explains that AUB will likely arise due to the techniques they use. It seems incongruous if the only ethical oversight body for that research were uninterested in this fact, given that it is a welfare cost of the research. We could further imagine that some of those performing these techniques could be graduate students or others who may be subordinate to those leading the research or managing facilities, and therefore potentially vulnerable. The AEC ought to be interested in AUB because these are ethically relevant facts about the research. They call for justification if they are present, and if they can be lessened or mitigated, that is an ethical improvement of that experiment.

Moore and Donnelly argue-in our view persuasively-that human participant research ethics committees should operate by assessing research relative to duly established coded standards. ${ }^{29}$ They argue that this is preferable to assessing research for its 'ethical acceptability', by which they mean, roughly, consistency with ethical reasoning. Their arguments apply equally persuasively to AECs. Accepting this view, we cannot argue comprehensively that it is an ethical improvement for research to be less psychologically harmful to laboratory animal personnel if by 'ethical' we mean conforming to explicit coded standards of AECs. These differ with jurisdiction and will vary in the scope they afford the AEC to consider the welfare of animal laboratory personnel. We believe that these are ethically deficient to the extent that they do not have standards directly protecting the welfare of those working with animals in research-such standards ought, we argue, to be created.

However, current standards do mean AECs should have regard for AUB, because this may make laboratory animal personnel less able to maintain high animal welfare standards, ${ }^{12}$ and some

\footnotetext{
iii However, we accept that AUB may be implicit in some aspects of ethical review. For example, the American Veterinary Medical Association includes aspects of AUB in their assessment of techniques covered in their 'Euthanasia Guidelines'. ${ }^{15}$ When AECs implement these guidelines, AUB may, to that extent, be implicitly addressed.
}

refinements to mitigate AUB are also refinements to promote animal welfare (eg, environmental enrichment). Therefore, AUB is indirectly relevant for protecting animal welfare, which is a key aim of AECs under their current standards.

However, the standards that AECs use should include a direct focus on AUB. The spirit of AECs is benevolent paternalism. They act to protect and advance the well-being of animals used in research, and the people who may benefit from it. They also ought to protect laboratory personnel from AUB where possible. Paternalism is a less controversial ethical option with animalslater, we will respond to an objection that the paternalism we advocate wrongs laboratory animal personnel, since they are moral agents.

Can AECs do this work? It would be a problem if we were arguing that they ought to do what they cannot do, even were standards changed. As argued, AECs standardly have regard to welfare, including human benefit from research, which shows that it would not be unfamiliar to them to be considering human welfare cost in the form of AUB. If applications to AECs explained and accounted for any AUB in the research including strategies to reduce or mitigate it, AEC members could reasonably be expected to be able to interpret and consider this, like any other information in an application. Other established ways of thinking on AECs, such as the three Rs could be adapted to be applied to AUB. Reducing animal numbers, refining techniques and replacing animals with non-sentient alternatives so that killing of sentient animals is unnecessary are obvious ways of reducing AUB which are a consequence of standard AEC operation currently. However, techniques can also be refined specifically so that they reduce or mitigate AUB, as we have described. Must humans be involved in the harming of animals, or is it possible for automation to replace them in ways that reduce harm to them while also satisfying the other requirements of ethical research?

\section{OBJECTIONS}

We have identified four potential objections to our argument. One is administrative in nature, and three are ethical.

First is the administrative objection. This accepts our argument that animal laboratory personnel face AUB but rejects our claim that AECs should be assessing and requiring reduction in this harm where possible. It should not be part of ethical review because it is a workplace health and safety concern and so ought to be handled by health and safety administration. Research ethics is concerned with protecting animal welfare and weighing this against the benefits of the research, not protecting researchers. Using health and safety administration is a consistent and administratively parsimonious regulatory response to deal with the problem and should therefore be preferred. ${ }^{\text {iv }}$

We agree that health and safety could help to address the problem we identify, and, to the extent that it did, this would be a reason to endorse this approach. However, we find scant evidence that this is routinely identified as a health and safety issue in animal research, with key health and safety guidance focusing on physical hazards, zoonoses and allergens. ${ }^{30}{ }^{31}$ This raises a sceptical concern that the health and safety apparatus may not be well suited to addressing the particular issue we raise. The same observation has been made by others regarding

\footnotetext{
${ }^{\text {iv }}$ This objection is adapted from Gillam, ${ }^{36}$ who argues against human participant research ethics committees playing a role in safeguarding researchers from physical and psychological risks they face in some qualitative research.
} 
research organisations' lack of health and safety protections for human participant researchers conducting qualitative research on sensitive topics, where researchers may also face a significant psychological tax. ${ }^{32}$ This is one of the reasons these authors also argue that human participant research ethics committees should undertake the sort of role we are advocating, rather than using health and safety processes.

Proposed guidelines for planning and conducting research have been updated in 2020 to state that it is 'vital to consider the mental health of those caring for these animals or observing this, to avoid compassion fatigue'. ${ }^{34}$ These guidelines are advice for researchers, however, not health and safety committees, or indeed AECs. In New Zealand, the National Animal Ethics Advisory Committee is currently reviewing their guidelines for researchers and AECs to include guidance on reducing compassion fatigue after discussion of the argument in a draft of this paper.

However, in animal ethics, treating this like a workplace safety issue could in some jurisdictions require AEC oversight. For example, Institutional Animal Care and Use Committees in the USA are required to assess occupational health and safety considerations as part of their review of integrity of the research, which includes review of experimental design. ${ }^{35}$

So, even if there was a health and safety approach adopted to addressing this issue, there is still reason to think that the AEC has an important role to play. The AEC is able to assess each project in detail and has the authority to prevent it from proceeding until it is satisfied that it is compliant with AEC standards, which we argue should include that potential harms to animal laboratory personnel are reduced where possible and are of an acceptable level.

The remaining three objections we wish to consider are more directly ethical in nature. The first, previously mentioned, relates to paternalism: if researchers or laboratory personnel decide to put their psychological health at risk, that is their choice-no justification is required for it. ${ }^{36}$ The only reason for interfering in a person's liberty is to protect others; protection against selfregarding harm lacks justification. Ethics committees therefore have no basis for inquiring into risks to researchers, or to require modifications or reject projects to protect those involved in the research.

For those who find seat belt and motorcycle helmet laws unjustified, this will be an appealing argument, and we accept that our proposal is unlikely to be convincing for them. For the rest, the fact that some lines of work affect the well-being of those doing the work is a legitimate public concern. ${ }^{33}$ Moreover, AUB, as we have argued, may affect not just the individuals working with laboratory animals but also their colleagues and broader institutions, as well as the quality of care they provide animals. ${ }^{10}$ This would therefore not be a purely paternalistic intervention by AECs focused on selfregarding choices.

The second relates to the moral appropriateness of AUB. Some may argue that harming or killing animals, even if justified, should elicit taxing emotions. To mitigate these would be wrong. This may be spelled out deontologically in terms of what we owe other animals, ${ }^{\mathrm{V}}$ or through a virtue theory lens as requirements for good character. ${ }^{37}$ However, it is not immediately clear what precisely is an appropriate response to justifiably (we are

${ }^{\mathrm{v}}$ See Korsgaard $^{39}$ for more on this way of approaching the morality of human-animal relationships. presuming) harming or killing animals in research that has passed ethical review. A case may be made that a sense of gratitude and an appreciation of the sacrifice made of laboratory animals are more fitting, ${ }^{38}$ and our proposal is compatible with this line of argument. Moreover, it is compatible with our proposal that those who administer these harms feel some negative emotion towards their actions. Our argument, as highlighted in the Welfare impact of harming animals in research section, focuses on AUB that is significantly disruptive to personnel's welfare and capacity to fulfil their professional roles.

Another way of voicing this concern relates to consequences. A significant degree of AUB may be central to motivating the search for more humane ways of using laboratory animals, and reducing the burden may diminish that motivation and make it easier to harm or kill greater numbers of laboratory animals. Both claims are not immediately implausible but are in need of empirical support before they could be considered persuasive. Such evidence would need to outweigh or contradict the evidence presented earlier that AUB can correspond with worse animal care,${ }^{10}$ and mitigating measures for AUB can correspond with improving animal welfare ${ }^{17}$ Even if these claims are persuasive, they imply that AECs should achieve ethical standards for reducing harm to animals by allowing harm from AUB to laboratory animal personnel. Aside from the potential ethical contradiction of reducing harm by allowing harm, existing policies, such as the three Rs implemented through AECs, and guidelines for researchers, ${ }^{34}$ reduce harm to animals without imposing it on others, which is the ethically preferable option.

\section{CONCLUSION}

We have argued that the procedures animal laboratory personnel carry out on animals can lead to psychological burdens that significantly impact their well-being and potentially that of the animals in their care. We have proposed that AECs should account for harm to these personnel from animal use, and responded to potential objections that (1) AECs are ill-equipped to do so, (2) that the proposal is too paternalistic, (3) that AUB is an appropriate response to the actions of these personnel and (4) that mitigating AUB may lead to worse treatment of research animals.

The well-being of laboratory animal personnel is currently neglected in ethical regulation of animal research. Media coverage of the impact of lockdown on these personnel from the culling has helped bring it to the fore, but it was already a serious problem in routine animal research. There is clear evidence that AUB is harmful and should be taken seriously. This requires more research into causes, methods for management, ethical evaluation and policy options to address it. We hope more regulators of animal research will support this work and regulate appropriately in response to it, and that organisations conducting animal research will research and pursue options for addressing AUB for the protection of both people and animals.

\section{Twitter Hazem Zohny @hazemzohny}

Acknowledgements The authors are grateful to two anonymous reviewers for their helpful comments on a previous draft of this paper.

Contributors Both authors contributed equally to the ideas and drafting of this paper; authorship order is based on alphabetical order.

Funding Open access publication fee for this article was paid by the Bioethics Centre, University of Otago. No other specific grant funding was received.

Competing interests MK is a member of the New Zealand National Animal Ethics Advisory Committee but is not writing in that capacity here.

Patient consent for publication Not required. 
Provenance and peer review Not commissioned; externally peer reviewed. Data availability statement All data relevant to the study are included in the article.

Open access This is an open access article distributed in accordance with the Creative Commons Attribution Non Commercial (CC BY-NC 4.0) license, which permits others to distribute, remix, adapt, build upon this work non-commercially, and license their derivative works on different terms, provided the original work is properly cited, appropriate credit is given, any changes made indicated, and the use is non-commercial. See: http://creativecommons.org/licenses/by-nc/4.0/.

ORCID iDs

Mike King http://orcid.org/0000-0002-7353-747X

Hazem Zohny http://orcid.org/0000-0002-7734-2186

\section{REFERENCES}

1 Ellison R. It takes a toll": researchers struggle with lockdown cull of lab mice. The Guardian, 2020. Available: https://www.theguardian.com/science/2020/jul/13/ laboratory-mice-cull-coronavirus-researchers-vivisection [Accessed 15 Sep 2020].

2 Parry M. Colleges Euthanized lab animals to protect employees from Covid-19. now they face an Onslaught of criticism. Chron. high. Educ, 2020. Available: https://www. chronicle.com/article/colleges-euthanized-lab-animals-to-protect-employees-fromcovid-19-now-they-face-an-onslaught-of-criticism/ [Accessed 20 Sep 2020].

3 Grimm D. It's heartbreaking.' Labs are euthanizing thousands of mice in response to coronavirus pandemic. Sci. AAAS, 2020. Available: https://www.sciencemag.org/ news/2020/03/it-s-heartbreaking-labs-are-euthanizing-thousands-mice-responsecoronavirus-pandemic [Accessed 20 Sep 2020].

4 Scott-Reid J. Mass killing of lab animals during pandemic calls into question necessity and cost of animal models. Sentient media, 2020. Available: https://sentientmedia. org/mass-killing-of-lab-animals-during-pandemic-calls-into-question-necessity-andcost-of-animal-models/ [Accessed 20 Sep 2020].

5 Nowogrodzki A. Cull, release or bring them home: coronavirus crisis forces hard decisions for Labs with animals. Nature 2020;580(7801):19.

6 Herzog H. Ethical aspects of relationships between humans and research animals. Ilar J 2002;43(1):27-32.

7 Reeve CL, Rogelberg SG, Spitzmüller C, et al. The Caring-Killing paradox: Euthanasia-Related strain among Animal-Shelter Workers1.J App/ Soc Psychol 2005;35(1):119-43.

8 Scotney RL, McLaughlin D, Keates HL. A systematic review of the effects of euthanasia and occupational stress in personnel working with animals in animal shelters, veterinary clinics, and biomedical research facilities. J Am Vet Med Assoc 2015:247(10):1121-30.

9 Rohlf V, Bennett P. Perpetration-induced traumatic stress in persons who euthanize nonhuman animals in surgeries, animal shelters, and laboratories. Soc Anim 2005;13(3):201-20

10 Newsome JT, Clemmons EA, Fitzhugh DC, et al. Compassion fatigue, euthanasia stress, and their management in laboratory animal research. J Am Assoc Lab Anim Sci 2019;58(3):289-92.

11 King M. Killing and feeling bad: animal experimentation and moral stress. Anim Stud J 2016:5:119-33.

12 Tremoleda JL, Kerton A. Creating space to build emotional resilience in the animal research community Lab Anim 2020:49(10):275-7.

13 Dowling T. Compassion does not fatigue! Can Vet J 2018;59(7):749-50.

14 Home Office. Annual statistics of scientific procedures on living animals great Britain 2019, 2019. Available: https://assets.publishing.service.gov.uk/government/uploads/ system/uploads/attachment_data/file/901224/annual-statistics-scientific-proceduresliving-animals-2019.pdf
15 AVMA (American Veterinary Medical Association). AVMA guidelines for the euthanasia of animals: 2020 edition. Schaumburg, Illinois: AVMA, 2020. https://www. avma.org/sites/default/files/2020-01/2020-Euthanasia-Final-1-17-20.pdf. (accessed 20/11/2020).

16 Gagea-lurascu M, Craig S. Euthanasia and Necropsy. In: Suckow MA, Stevens KA, Wilson RP, eds. The laboratory rabbit, guinea pig, hamster, and other rodents. Boston: Academic Press, 2012: 117-39.

17 LaFollette MR, Riley MC, Cloutier S, et al. Laboratory animal welfare meets human welfare: a cross-sectional study of professional quality of life, including compassion fatique in laboratory animal personnel. Front Vet Sci 2020;7.

18 Hayes GM, LaLonde-Paul DF, Perret JL, et al. Investigation of burnout syndrome and job-related risk factors in veterinary technicians in specialty teaching hospitals: a multicenter cross-sectional study. J Vet Emerg Crit Care 2020;30(1):18-27.

19 Engel RM, Silver CC, Veeder CL, et al. Cognitive dissonance in laboratory animal medicine and implications for animal welfare. J Am Assoc Lab Anim SCi 2020;59(2):132-8.

20 Overhulse K. Coping with lab animal morbidity and mortality: a trainer's role. Lab Anim 2002:31:39-43.

21 Hooper C, Craig J, Janvrin DR, et al. Compassion satisfaction, burnout, and compassion fatigue among emergency nurses compared with nurses in other selected inpatient specialties. J Emerg Nurs 2010;36(5):420-7.

22 Smart D, English A, James J, et al. Compassion fatigue and satisfaction: a crosssectional survey among US healthcare workers. Nurs Health Sci 2014:16(1):3-10.

23 Reeve CL, Spitzmuller C, Rogelberg SG, et al. Employee reactions and adjustment to euthanasia-related work: identifying turning-point events through retrospective narratives. J Appl Anim Welf Sci 2004;7(1):1-25.

24 Rogelberg SG, DiGiacomo N, Reeve CL, et al. What shelters can do about euthanasiarelated stress: an examination of recommendations from those on the front line. $J$ Appl Anim Welf Sci 2007:10(4):331-47.

25 Smith P. Compassion satisfaction:: 50 steps to healthy caregiving. 1st edition. CreateSpace Independent Publishing Platform, 2012.

26 National Animal Ethics Advisory Committee. Good practice guide: for the use of animals in research, testing and teaching. Wellington, New Zealand: Ministry for Primary Industries, 2019. https://www.agriculture.govt.nz/dmsdocument/33585good-practice-guide-for-the-use-of-animals-in-research-testing-and-teaching (accessed 8 Sep 2020).

27 Mohan S, Foley PL. Everything you need to know about Satisfying IACUC protocol requirements. Ilar J 2019;60(1):50-7.

28 RSPCA, LASA. Guiding principles on good practice for animal welfare and ethical review bodies, 2015. Available: https://www.lasa.co.uk/PDF/AWERB_Guiding_ Principles_2015_final.pdf [Accessed 9 Sep 2020].

29 Moore A, Donnelly A. The job of 'ethics committees'. J Med Ethics 2018:44(7):481-7.

30 Institute of Laboratory Animal Resources (U.S.). Occupational health and safety in the care and use of research animals. Washington, DC: National Academy Press, 1997.

31 Great Britain, Advisory Committee on Dangerous Pathogens. Working safely with research animals: management of infection risks. Norwich: HSE Books, 1997.

32 Dickson-Swift V, James EL, Kippen $\mathrm{S}$, et al. Blurring boundaries in qualitative health research on sensitive topics. Qual Health Res 2006;16(6):853-71.

33 Dickson-Swift V, James EL, Kippen S. HRECS have an important role to play in researcher safety. Aust N Z J Public Health 2005;29(6):581-2.

34 Smith AJ. Guidelines for planning and conducting high-quality research and testing on animals. Lab Anim Res 2020;36:21.

35 Mohan S, Huneke R. The role of IACUCs in responsible animal research. Ilar J 2019;60(1):43-9.

36 Gillam L. Protecting researchers is not the role of HRECs. Aust N Z J Public Health 2005;29(6):580-1.

37 Rebecca WL. Virtue ethics and laboratory animal research. Ilar J 2020. doi:10.1093/ ilar/ilaa015. [Epub ahead of print: 27 Jul 2020]

38 Iliff SA. An additional "R": remembering the animals. Ilar J 2002:43(1):38-47.

39 Korsgaard CM. Fellow creatures: our obligations to the other animals. Oxford: OUP Oxford, 2018. 